\title{
ANALISIS EFISIENSI DAN EFEKTIFITAS OPERASI KAPAL PURSE SEINEDI PELABUHAN PERIKANAN NUSANTARA TERNATE PROVINSI MALUKU UTARA
}

\author{
Munawir Muhammad* \\ Staf Pengajar FAPERTA UMMU Ternate, Email: -
}

\begin{abstract}
ABSTRAK
Penelitian ini tentang kegiatan operasi kapal Purse Seine. Yang dilaksanakan pada bulan Desember 2016 di Pelabuhan Perikanan Nusantara Ternate. Penelitian ini bertujuan untuk (1) mengetahui tingkat efisiensi operasi Purse Seine di Pelabuhan Perikanan Nusantara Ternate. (2). mengetahui tingkat efektifitas operasi Purse Seine di Pelabuhan Perikanan Nusantara Ternate. Metode yang digunakan yaitu data primer dan data sekunder yang bersifat kuantitatif. Hasil dari penelitian ini menunjukan bahwa nilai rata-rata investasi untuk usaha Purse Seine kecil sebesar $R p$ 186,160,875 sedangkan investasi usaha Purse Seine besar nilai rata-rata sebesar $R p$ 414,287,500. dengan produksi untuk Purse Seine ukuran GT kecil kelompok satu memiliki nilai rata-rata 29,742 $\mathrm{kg}$ per tahun, sedangkan produksi ukuran GT besar kelompok dua memiliki nilai rata-rata 48,415 kg. dari analisis perhitungan usaha unit penangkapan Purse Seine kecil diperoleh ratarata penerimaan total $R p$ 359,419,500,- biaya total 276,283,327,- keuntungan 83,136,173,- R/C 13,140,- Payback period 48,144,- sedangkan untuk kapal Purse Seine besar diperoleh nilai rata-rata penerimaan total $R p$ 567,295,625,- dengan biaya total $R p$ 441,009,765,- keuntungan $R p$ 126,285,860,- R/C 12,734,- Payback period 39,389,- Hal ini menunjukan bahwah usaha Purse Seine kecil dapat bersaing dengan kapal Purse Seine yang berukuran lebih besar.
\end{abstract}

Kata Kunci: Operasi Kapal Purse Seine, Produksi, Efisiensi, Efektifitas.

I. PENDAHULUAN

1.1. Latar Belakang

Kegiatan Perikanan tangkap menggunakan alat tangkap Purse Seine di Kota Ternate berkembang dengan baik, hal ini didukung dengan berdirinya Pelabuhan Perikanan Nusantara. Pelabuhan Perikanan Nusantara merupakan salah satu Pelabuhan Perikanan yang ada di Provinsi Maluku Utara khususnya di Kota Ternate yang berperan serta dalam membangun kelautan dan Perikanan. Pelabuhan Perikanan Nusantara Ternate dibangun pada tahun 1978 dengan berbagai sarana dasar, sarana fungsional, dan sarana penunjang. Pelabuhan Perikanan Nusantara Ternate merupakan satu-satunya Pelabuhan tipe B yang ada di perairan Maluku Utara (Anonimous, 2014).
Produksi hasil perikanan tangkap yang didaratkan di Pelabuhan Perikanan Nusantara Ternate merupakan hasil tangkapan kapal perikanan dengan alat tangkap Purse Seine. Hasil tangkapan yang didaratkan di Pelabuhan Perikanan Nusantara Ternate memiliki ukuran dan jenis ikan yang berbeda-beda (Anonimous, 2015)

Purse Seine disebut juga "pukat cincin" karena alat tangkap ini dilengkapi dengan cincin untuk mana "tali cincin" atau "tali kerut" di lalukan di dalamnya. Fungsi cincin dan tali kerut/tali kolor ini penting terutama pada waktu pengoperasian jaring. Sebab dengan adanya tali kerut tersebut jaring yang tadinya tidak berkantong akan terbentuk pada tiap akhir penangkapan. Prinsip menangkap ikan dengan Purse Seine adalah dengan melingkari suatu gerombolan ikan dengan jaring, setelah 
itu jaring bagian bawah dikerucutkan, dengan demikian ikan-ikan terkumpul di bagian kantong. Dengan kata lain dengan memperkecil ruang lingkup gerak ikan. Ikanikan tidak dapat melarikan diri dan akhirnya tertangkap. Fungsi mata jaring dan jaring adalah sebagai dinding penghadang, dan bukan sebagai pengeretikan (Fiqrin, 2010).

Kegiatan yang dilakukan para nelayan dalam operasi Purse Seine yaitu meliputi persiapan kapal, mesin kapal, alat tangkap, peralatan dan perlengkapan tambahan, serta perbekalan. Kelima persiapan tersebut sangat diperlukan dalam penangkapan ikan menggunakan alat tangkap Purse Seine.

Informasi tentang unit penangkapan Purse Seine yang efektif dan memiliki produktivitas yang tinggi merupakan hal yang penting dalam mengembangan kegiatan perikanan tangkap di Kota Ternate. Usaha penangkapan ikan menggunakan alat tangkap Purse Seine diharapkan dapat meguntungkan dan bisa terus berkelanjutan, untuk itu penelitian mengenai operasi penangkapan ikan menggunakan alat tangkap Purse Seine perlu dilakukan dengan mempertimbangkan seluruh aspek yang terkait.

Diharapkan operasi Purse Seine akan Efisien bila mana keluaran (Output) lebih besar dari masukan (input). sedangkan dikatakan efektif yaitu karena kegiatan operasinya Purse Seine sangat meningkatkan hasil tangkapan yang lebih banyak.

Berdasarkan latar belakang yang dikemukakan diatas maka peneliti termotivasi untuk mengkaji "Analisis Kegiatan Dan Strategi Pengembangan Penangkapan Pada Kapal Purse Seine (Studi Kasus Pelabuhan Perikanan Nusantara Ternate).

\subsection{Tujuan Penelitian}

1. Menentukan tingkat efisiensi operasi kapal Purse Seine di Pelabuhan Perikanan Nusantara Ternate.

2. Menentukan tingkat efektifitas operasi kapal Purse Seine di Pelabuhan Perikanan Nusantara Ternate.

\section{METODE PENELITIAN}

\subsection{Waktu dan Tempat Penelitian}

Penelitian ini dilaksanakan pada bulan Desember 2016. yang bertempat di Pelabuhan Perikanan Nusantara (PPN) Ternate, Propinsi Maluku Utara. Pemilihan lokasi penilitian karena Pelabuhan Perikanan Nusantara Ternate merupakan satu-satunya pelabuhan sebagai infrastuktur pendukung usaha yang mempunyai fungsi untuk melayani operasional kapal perikanan yang menggunakan alat tangkap Purse Seine.

\subsection{Metode Pengumpulan Data}

Metode pengambilan data yang digunakan ini adalah pengumpulan data primer dan data sekunder. Data sekunder diperoleh dari catatan dan laporan dari Tempat Pendaratan Ikan (TPI) Pelabuhan Perikanan Nusantara Ternate dan Dinas Perikanan dan Kelautan di Pelabuhan Perikanan Nusantara. Data sekunder tambahan yang dikumpulkan meliputi: kondisi umum daerah secara geografis dan administratif, kondisi umum perikanan tangkap di lokasi, dan informasi perikanan purse seine (jumlah kapal, jumlah nelayan, jumlah pengolah).

\subsection{Metode Penarikan Sampel}

Populasi adalah unit alat tangkap Purse Seine di Pelabuhan Perikanan Nusantara Ternate yang berjumlah sebanyak 32 kapal. dimana yag diteliti sebanyak 16 unit kapal Purse Seine yang dibagi menjadi dua kelompok yaitu kelompok pertama adalah 8 unit penangkapan Purse Seine dengan ukuran kapal $<10$ GT dan kelompok kedua $>10$ GT adalah 8 unit dengan ukuran kapal (14 sampai 28 GT ).

Teknik Pengambilan sampel dilakukan dengan cara Disproportionate Stratifiet Random Sampling . Teknik ini digunakan bila populasi berstrata tapi kurang proposional .

\subsection{Metode Analisis Data}

Analisis data yang digunakan penulis dalam penelitian ini adalah metode kuantitatif yaitu peneliti berusaha memberikan keterangan dan penjelasan mengenai masalah yang berhubungan dengan penelitian berdasarkan teori pemahaman secara mendalam tentang objek penelitian terkait 
kegiatan operasi kapal purse seine dari $\exists$ persiapan, penentuan daerah penangkapan ikan, perjalanan, proses penangkapan, pengangkutan dan pengelolaan. Kemudian data ditabulasi dan dianalisis secara matematis, didasarkan pada hasil pengumpulan data dan analisis kuisioner.

\subsection{Analisis Efektivitas dan Efisiensi}

Analisis Efektivitas dan Efisiensi digunakan untuk mengetahui tingkat efektivitas dan efisiensi dari kegiatan operasi kapal purse seine. Dengan pertimbangan data yang diambil dari tiap kapal relatif homogen, maka analisis efisiensi dilakukan setelah data unit penangkapan purse seine yang diteliti dibagi menjadi dua kelompok menurut ukuran kapal (Suharto, 2003 dalam Erlangga, 2008)

Penilaian terhadap analisis efektivitas dilakukan untuk membandingkan output dengan input dari masing-masing unit purse seine. Input dari unit penangkapan adalah (X1) gross tonage (GT) kapal, (X2) kekuatan mesin (PK), (X3) bahan bakar,(X4) jumlah ABK, dan (X5) luas jaring purse seine. Output yang digunakan untuk efektivitas adalah produksi kotor per tahun, sedangkan output yang digunakan untuk efisiensi adalah nilai produksi kotor per tahun

Efektifitas dari unit penangkapan purse seine di Pelabuhan Perikanan Nusantara Ternate dirumuskan sebagai berikut :

X1 = Produksi Kotor : Gross Toneage (GT) Kapal

X2 = Produksi Kotor : Kekuatan Mesin (PK)

X3 = Produksi Kotor : Bahan Bakar (Ton)

X4 = Produksi Kotor : Jumlah ABK (Orang)

X5 = Produksi Kotor : Luas Jaring Purse Seine (M2)

Efisiensi dari unit penangkapan purse seine di Pelabuhan Perikanan Nusantara Ternate dirumuskan sebagai berikut :
X1 = Zilai Produksi Kotor (Rp) : Gross Toneage (GT) Kapal
X2 = Nilai Produksi Kotor (Rp) : Kekuatan Mesin (PK)
X3 = Nilai Produksi Kotor (Rp) : Bahan Bakar (Ton)
X4 = Nilai Produksi Kotor (Rp) : Jumlah ABK (Orang)

X5 = Nilai Produksi Kotor (Rp) : Luas Jaring Purse Seine (M2)

Pada penilaian semua kriteria secara terpadu, dilakukan standarisasi nilai. Standarisasi nilai dapat dilakukan dengan menerapkan dua macam fungsi yaitu pertukaran (trade off) dan fungsi nilai (Haluan j, dan Nurani, T.W, 1988 )

Selanjutnya digunakan metode scoring, metode ini dilakukan pada penilaian-penilaian untuk kriteria yang mempunyai satuan berbeda.

Standarisasi dengan fungsi nilai dapat dilakukan dengan memakai persamaan sebagai berikut: (Haluan,J, dan Nurani, T.W, 1988).

$$
\begin{array}{r}
V(x)=\frac{(X-X o)}{(X 1-X o)} \\
i=n \\
V(A)=\quad V i(X i) \\
i=1
\end{array}
$$

\section{Keterangan:}

$$
\begin{array}{ll}
V(x) & =\text { Fungsi nilai dari variabel } X \\
X & =\text { Variabel } X \\
X o & =\text { Nilai terburuk pada kriteria } X \\
X 1 & =\text { Nilai terbaik pada kriteria } X \\
V(A) & =\text { Fungsi nilai dari alternatif } A \\
V i(X i) & =\text { Fungsi nilai dari alternatif pada } \\
& \text { kriteria ke-i } \\
X i & =\text { Kriteria ke-i }
\end{array}
$$

Urutan prioritas dimulai dari nilai tertinggi ke nilai terendah. Dengan menggunakan fungsi nilai maka urutan prioritas ditetapkan secara urut dari alternatife yang mempunyai nilai fungsi tertinggi ke alternatif dengan nilai fungsi terendah.

\section{HASIL DAN PEMBAHASAN}

\subsection{Unit Purse Seine}

Purse Seine merupakan alat tangkap yang paling banyak memberikan kontribusi bagi produksi ikan laut di Pelabuhan Perikanan Nusantara Ternate. Unit penangkapan yang dominan menangkap ikan komoditas unggulan dan memiliki produktivitas tertinggi dari keseluruhan unit penangkapan yang ada di Ternate yaitu unit penangkapan purse seine. Purse Seine itu sendiri adalah alat penangkapan ikan yang berbentuk kantong dilengkapi dengan cincin dan tali Purse Line yang terletak 
dibawah tali ris, alat tangkap ini banyak memberikan kontribusi bagi produksi Ikan laut di Kota Ternate (PPN Ternate 2015).

\subsubsection{Kapal Purse Seine}

Pada umumnya kapal yang digunakan oleh nelayan-nelayan di Pelabuhan Perikanan Nusantara Ternate terbuat dari jenis kayu jati (Tectona grandis). Kapal-kapal yang digunakan berbeda-beda tergantung ukuran dari masingmasing kapal. Daya tahan kapal dari jenis kayu jati ini memiliki ketahanan yang cukup lama mencapai 5-7 tahun, daya tahan ini dibutuhkan selama pelayaran menuju daerah penangkapan, ketika melakukan operasi penangkapan dan sewaktu melakukan pelayaran kembali ke pelabuhan. Kapal Purse Seine yang ada di PPN (Pelabuhan Perikanan Nusantara) memiliki ukuran GT yang bervariasi, dengan kisaran 5 sampai 28 GT. (PPN Ternate, 2014).

Nama dan spesifikasi kapal sampel yang diteliti seperti terlihat pada Tabel 1.

Tabel 1. Nama dan Spesifikasi Kapal Sampel Penelitian

\begin{tabular}{clccccc}
\hline No & \multicolumn{1}{c}{ Nama Kapal } & GT & $\begin{array}{c}\text { P } \\
(\mathrm{m})\end{array}$ & $\begin{array}{c}\text { L } \\
(\mathrm{m})\end{array}$ & $\begin{array}{c}\text { D } \\
(\mathrm{m})\end{array}$ & $\begin{array}{c}\text { Jumlah } \\
\text { Palkah }\end{array}$ \\
\hline 1 & PMN Adi Poetra - 03 & 6 & 13,75 & 2,50 & 1,00 & 6 \\
2 & KM Melati & 5 & 14,00 & 3,00 & 1,00 & 2 \\
3 & KM Warben & 5 & 13,20 & 2,90 & 1,00 & 2 \\
4 & KMN Qaulan-05 & 6 & 12,74 & 2,71 & 0,81 & 6 \\
5 & KMN Lumbung jaya & 5 & 12,50 & 2,50 & 1,00 & 2 \\
6 & KMN Qaulan-03 & 6 & 12,73 & 2,70 & 0,80 & 6 \\
7 & Cenderawasih-01 & 6 & 14,00 & 2,80 & 1,00 & 6 \\
8 & Qausar-03 & 6 & 12,50 & 3,60 & 1,20 & 6 \\
9 & Matororo-01 & 14 & 12,98 & 3,46 & 1,58 & 7 \\
10 & Matororo-03 & 14 & 12,98 & 3,46 & 1,58 & 7 \\
11 & Matororo-05 & 14 & 12,98 & 3,46 & 1,58 & 7 \\
12 & Bahari Berkesan-01 & 16 & 11,72 & 3,30 & 1,65 & 7 \\
13 & Lentera-44 & 18 & 14,34 & 4,17 & 1,25 & 7 \\
14 & Nusantara Kirana & 23 & 21,46 & 3,20 & 1,30 & 8 \\
15 & Pratama Putra & 26 & 18,00 & 4,35 & 1,60 & 8 \\
16 & Ratu Rosari & 28 & 19,12 & 4,86 & 1,35 & 8 \\
\hline
\end{tabular}

Sumber: PPN Ternate, 2015

Keterangan: GT : Gross Toneage Kapal

$P \quad$ : Panjang $(m)$

L : Lebar (m)

D :Dalam (m)

\subsubsection{Alat Penangkap Ikan (Purse Seine)}

Alat tangkap Purse Seine sudah cukup lama dikenal oleh masyarakat nelayan. Alat tangkap Ikan ini terdiri dari bagian sayap dan bagian kantong yang ukuranya ditentukan oleh panjang dan lebarnya alat tangkap Purse Sine. purse seine terbagi dalam dua bagian besar yaitu badan/tubuh jaring, kantong dan bagian selvadge atau jaring penguat. Bagian tubuh jaring terbuat dari bahan yang halus, sehingga dapat mengurangi daya tahan terhadap arus. Sebaliknya, pada bagian kantong badannya harus lebih kuat agar dapat menahan gaya tegang atau goncangan yang disebabkan oleh ikan-ikan hasil tangkapan yang berkumpul pada bagian kantong sedangkan pada bagian selvadge digunakan untuk melindungi jaring bagian atas dan bawah terhadap gaya tegang dan terbuat dari bahan yang lebih berat dari bagian kantong. Bagian sisi bawah diusahakan dapat tenggelam secepat mungkin karena penggunaan Purse Seine pada umumnya bertujuan untuk menangkap ikan pelagis. Alat tersebut diharapkan dapat melingkari gerombolan ikan dengan cepat, untuk mencegah ikan melarikan diri dapat dilakukan dengan membuat dinding jaring yang cukup lebar dan mengurung gerombolan ikan ke dalam lingkaran secepat mungkin.

\subsubsection{Nelayan Purse Seine}

Kegiatan penangkapan Ikan menggunakan alat tangkap Purse Seine di 


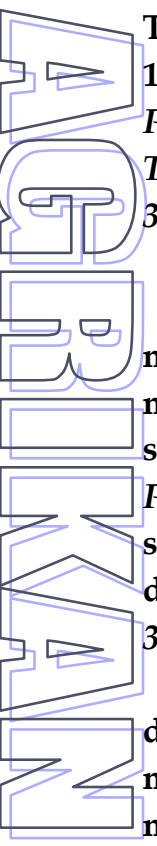

Ternate menggunakan tenaga kerja berjumlah 13 sampai 20 orang pada masing-masing Kapal Purse Seine tergantung pada ukuran besar Gross Toneage (GT) kapal yang digunakan.

3.1.4. Kegiatan Operasi Penangkapan Ikan dengan Purse Seine

Kegiatan Operasi penangkapn menggunakan alat tangkap Purse Seine dibagi menjadi tiga tahap, yaitu tahap persiapan sebelum kapal melaut, tahap penurunan jaring Purse Seine yang dilakukan pada jam 05:00 subuh dan tahap penarikan jaring yang dilakukan pada jam 08:00 pagi.

3.1.5. Persiapan

Kapal Purse Seine Ternate terlebih dahulu melakukan tahapan persiapan dan melengkapi perbekalan sebelum berangkat melaut. Persiapan yang dilakukan meliputi persiapan kapal, mesin kapal, alat tangkap, peralatan dan perlengkapan tambahan, serta perbekalan.

\section{Persiapan Kapal}

Sebelum kapal Purse Seine melaut yang pertama kali dilakukan oleh para ABK/nelayan yaitu mempersiapkan segala sesuatunya yang berhubungan dengan kapal yang akan melaut, contohnya yaitu kapal akan diperikasa terlebih dahulu agar terhindar dari sesuatu yang menjadi kendala pada saat proses operasi kapal, yaitu dengan cara memeriksa kapal, jika terjadi kebocoran maka akan segera diperbaiki.

2. Persiapan Alat Tangkap
Persiapan alat tangkap sangat penting dilakukan sebelum operasi kapal berlangsung, karena jika terjadi kerusakan pada jarring Purse Seine akan menghambat proses penangkapan ikan, untuk itu jaring terlebih dahulu harus diperiksa apakah ada yang sobek dan agar segera diperbaiki.

\section{Persiapan Mesin Kapal}

Sebelum kapal beroperasi maka yang dilakukan yaitu memeriksa mesin dalam keadaan menyala agar dapat mempermudah untuk mengetahui adanya mesin yang tidak berjalan lancar.

\section{Persiapan Peralatan dan Perlengkapan Tambahan}

ABK/nelayan Purse Seine sebelum memulai operasi biasanya membawa semua perlatan dan perlengkapan tambahan yang akan dibawa pada saat kapal beroperasi. Diantaranya sebagai berikut :

a. Rumpon daun kelapa

Rumpon daun kelapa ini dibawa untuk mengumpulkan ikan agar mudah ditangkap

b. Lampu Tawur

Lampu tawur digunakan sebagai tanda tebar jaring dimalam hari saat melakukan operasi penangkapan ikan

\section{c. Persiapan Perbekalan}

Kapal Purse Seine di Ternate membawa cukup banyak perbekalan untuk memenuhi kebutuhan operasi penangkapan Ikan, baik untuk kapal, mesin kapal, maupun ABK/Nelayan. Bisa dilihat pada Tabel 2.

Tabel 2. Biaya Operasi Per Trip pada Kapal Purse Seine di Pelabuhan Perikanan Nusantara Ternate

\begin{tabular}{lccr}
\hline \multicolumn{1}{c}{ Jenis Perbekalan } & Nilai & Satuan & Harga \\
\hline Solar & 11.200 & Liter & Rp 81.200.000 \\
Bengsin & 800 & Liter & Rp 5.600.000 \\
Minyak Tanah & 10.710 & Liter & Rp 53.550.000 \\
Oli & 1.603 & Liter & Rp 67.326.000 \\
Es Balok & 1.520 & Liter & Rp 27.360.000 \\
Air Tawar & 16.000 & Liter & Rp 160.000 .000 \\
Beras dan Lauk Pauk & Ratusan & Kg & Rp 31.700.000 \\
\hline Total & & & Rp 426.736.000 \\
\hline
\end{tabular}

Sumber : Data Primer, diolah, 2016

Jika dilihat pada Tabel diatas dapat diketahui bahwa saat kapal-kapal Purse seine akan melaut membawa cukup banyak perbekalan dan mengeluarkan dana yang cukup besar untuk pembelian perbekalan. 3.1.6 Penentuan Derah Penangkapan Ikan
Sebelum kapal mulai beroperasi, pertama kali yang harus dilakukan yaitu menentukan daerah penanagkapan ikan, Pada umunya ABK/nelayan Purse Seine di Kota Ternate melakukan penangkpan ikan diluar perairan Kota Ternate agar mendapatkan hasil 


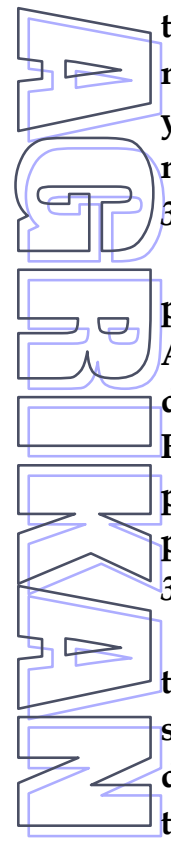

tangkapan yang lebih banyak dan menguntungkan. Daerah penangkapan ikan yaitu di Halmahera bagian Selatan yang meliputi Bacan, Kayoa, Obi, dan Gane Barat.

3.1.7 Perjalanan

Selama perjalanan menuju tempat penangkapan ikan yang telah ditentukan, para ABK/nelayan banyak memanfaatkan waktu dengan bersantai dan mendengarkan musik. Hal itu dilakukan agar tidak membuat jenuh para nelayan selama perjalanan menuju tempat penangapan ikan.

3.1.8 Pelaksanaan Operasi Penangkapan Ikan

Operasi penangkapan ikan dengan alat tangkap Purse Seine dilakukan pada waktu subuh sampai jam 8 pagi. Tahapan-tahapan dalam operasi penangkapan ikan dengan alat tangkap Purse Seine adalah sebagai berikut :

1. Pemasangan Rumpon

Rumpon merupakan alat bantu dalam operasi penangkapan ikan dengan menggunakan alat tangkap Purse Seine. Fungsinya juga sebagai tempat berkumpulnya ikan. Pemasangan rumpon dilakukan dengan cara mengikat rumpon daun kelapa dengan menggunakan tali dan ditaruh di bagian bawah rakit yang terbuat dari bambu.

\section{Penentuan daerah penangkapan}

Ditentukan berdasarkan pengalaman para $\mathrm{ABK} /$ nelayan, mereka menentukan daerah penangkapan dengan melihat keadaan air laut yang cerah, arus yang kencang, dan angin yang sedang bertiup

3. Penyalaan lampu listrik diatas kapal

Penyalaan lampu listrik dilakukan ketika mendapatkan tempat penangkapan ikan yang dirasa tepat oleh para $\mathrm{ABK} /$ nelayan. Setelah lampu listrik diatas kapal menyala, jangkar diturunkan untuk berlabuh, mesin kapal dimatikan agar tidak menggangu proses penangkapan ikan.

4. Penurunan Jaring (setting)

Penurunan jaring harus memperhatikan arah arus dan angin terhadap posisi kapal. Hal ini bertujuan agar jaring dapat melingkar secara sempurna dan tidak terbawah arus kebawah kapal.

\section{Penarikan Jaring}

Penarikan jaring di lakukan setelah tahap setting selesai yaitu dari jam 05.00 subuh sampai jam 08.00 pagi. Dengan menarik tali kolor kemudian badan jaring dan pemberat. Hal ini dimaksudkan agar bagian bawah mengkerut dan membentuk kantong. Untuk penarikan jaring dilakukan oleh seluruh ABK/nelayan.

6. Penanganan Ikan Diatas Kapal

Ikan yang sudah didapat disortir menurut jenis dan ukurannya terlebih dahulu, sebelum dimasukan ke dalam palkah atau tempat penyimpanan ikan yang sudah diberi es balok.

\section{Pendaratan}

Ikan yang sudah dimasukan kedalam palkah, diambil menggunakan serok dan dimasukan kedalam keranjang, setelah itu para ABK/nelayan mengangkut ikan tersebut ke tempat bangsal pembongkaran ikan.

\subsection{Analisis Usaha Unit Penangkapan Purse Seine di Ternate}

Analisis usaha terdiri dari biaya investasi, biaya tidak tetap, biaya tetap, jumlah trip, dan jumlah tenaga kerja (ABK). Yang tergolong biaya investasi adalah biaya pembelian kapal, mesin, alat tangkap, lampu pemikat Ikan, dan perlengkapan tambahan seperti keranjang Ikan, drum bahan bakar solar, drum minyak tanah, drum pelumas, dan bak air tawar, serta peralatan untuk memasak. Biaya tidak tetap terdiri dari biaya pembelian solar, Oli, minyak tanah, dan lain-lain yang di hitung selama 4 trip. Sedangkan biaya tetap meliputi biaya penyusutan, biaya perijinanan SIUP dan biaya gaji ABK/nelayan. Jumlah trip pertahun didapatkan dari rata-rata jumlah trip pertahun, bisa dilihat pada Tabel 3 .

Pada unit penangkapan Purse Seine kelompok satu memiliki biaya investasi yang lebih rendah karena harga dari kapal, mesin, dan alat tangkap yang digunakan lebih rendah dibandingkan pada unit penangkapan Purse Seine kelompok ke dua. Biaya tetap ini terdiri dari biaya penyusutan, gaji $\mathrm{ABK} /$ nelayan dan biaya perizinan. Biaya penyusutan dipengaruhi oleh daya tahan unit penangkapan (kapal,mesin dan alat tangkap). Unit penangkapan Purse Seine kelompok satu memiliki biaya tetap yang lebih rendah karena biaya gaji ABK/nelayan yang dikeluarkan lebih rendah dibandingkan dengan unit penangkapan Purse Seine kelompok kedua. 
Pada Tabel 3 dapat dilihat bahwa nilai rata-rata kedua kelompok tersebut yang memiliki nilai rata-rata tertinggi adalah kelompok 2, dengan Gross Toneage (GT) ratarata sebesar 19.125,- dan rata-rata nilai Invesatasi sebesar $414,287,500$,- biaya tidak tetap sebesar $76,815,000$,- biaya tetap dengan nilai rata-rata sebesar $364,194,765$,- sedangkan nilai rata-rata dari jumlah trip/tahun adalah 4 dan nilai rata-rata dari jumlah ABK adalah sebesar 18.375,-

Tabel 3. Data Biaya Investasi, Biaya Tidak Tetap, Biaya Tetap, Jumlah Trip/Tahun, Dan Jumlah Tenaga Kerja Dari Unit Penangkapan Purse Seine di Pelabuhan Perikanan Nusantara Ternate

\begin{tabular}{|c|c|c|c|c|c|c|}
\hline Kapal & GT & $\begin{array}{c}\text { Biaya } \\
\text { Investasi } \\
(\mathrm{Rp}) \\
\end{array}$ & $\begin{array}{c}\text { Biaya } \\
\text { Tidak } \\
\text { Tetap (RP) } \\
\end{array}$ & $\begin{array}{c}\text { Biaya Tetap } \\
\text { (RP) }\end{array}$ & $\begin{array}{c}\text { Jumlah } \\
\text { Trip per } \\
\text { tahun }\end{array}$ & $\begin{array}{c}\text { Jumlah } \\
\text { Tenaga } \\
\text { Kerja }\end{array}$ \\
\hline \multicolumn{7}{|l|}{ Kelompok 1} \\
\hline Adi Poetra -03 & 6 & $233,290,000$ & $60,440,000$ & $261,946,026$ & 4 & 15 \\
\hline Qaulan-05 & 6 & $204,270,000$ & $62,840,000$ & $223,399,720$ & 4 & 15 \\
\hline Qaulan-03 & 6 & $183,690,000$ & $62,840,000$ & $227,854,679$ & 4 & 15 \\
\hline KM Melati & 5 & $182,790,000$ & $64,040,000$ & $204,683,382$ & 4 & 13 \\
\hline KM Warben & 5 & $99,075,000$ & $24,184,000$ & $203,097,205$ & 4 & 13 \\
\hline Lumbung Jaya & 5 & $169,342,000$ & $57,040,000$ & $146,470,922$ & 4 & 13 \\
\hline Cenderawasih & 6 & $216,890,000$ & $60,440,000$ & $248,656,882$ & 4 & 15 \\
\hline Qausar-03 & 6 & $199,940,000$ & $61,240,000$ & $241,093,797$ & 4 & 15 \\
\hline Rata-rata & 5.63 & $186,160,875$ & $56,633,000$ & $219,650,327$ & 4 & 14.25 \\
\hline \multicolumn{7}{|l|}{ Kelompok 2} \\
\hline Matororo-01 & 14 & $344,790,000$ & $71,040,000$ & $371,338,935$ & 4 & 17 \\
\hline Matororo-03 & 14 & $347,790,000$ & $71,040,000$ & $290,063,411$ & 4 & 17 \\
\hline Matororo-05 & 14 & $346,890,000$ & $71,840,000$ & $235,639,058$ & 4 & 17 \\
\hline Bahari B & 16 & $383,830,000$ & $72,640,000$ & $322,332,582$ & 4 & 18 \\
\hline Lentera-44 & 18 & $406,030,000$ & $73,840,000$ & $338,883,404$ & 4 & 18 \\
\hline Nusantara & 23 & $465,490,000$ & $76,640,000$ & $425,404,038$ & 4 & 20 \\
\hline \multicolumn{7}{|l|}{ Kira } \\
\hline Pratama Putra & 26 & $482,690,000$ & $79,940,000$ & $442,718,906$ & 4 & 20 \\
\hline Ratu Rosari & 28 & $536,790,000$ & $97,540,000$ & $487,177,787$ & 4 & 20 \\
\hline Rata-rata & 19.125 & $414,287,500$ & $76,815,000$ & $364,194,765$ & 4 & 18.375 \\
\hline
\end{tabular}

Penerimaan total didapat dari nilai produksi kotor pertahun, biaya total didapatkan dari jumlah biaya tetap ditambah biaya tidak tetap, Sedangkan keuntungan dihitung dari total penerimaan dikurangi dengan total biaya, dan $\mathrm{R} / \mathrm{C}$ dihitung dari penerimaan total dibagi biaya total. Sedangkan Payback Period dihitung dari biaya investasi dibagi dengan keuntungan bisa dilihat pada Tabel 4.

Berdasarkan perhitungan, didapatkan nilai rata-rata pada kelompok pertama yaitu dengan penerimaan total sebesar
Rp359,419,500,- biaya total dengan nilai ratarata Rp276,283,327,- Keuntungan rata-rata yang diperoleh dari usaha ini adalah sebesar Rp83,136,173,- R/C nilai rata-rata sebesar 13,140,-. dan nilai Payback Period sebesar 48,144,-. $\quad$ sedangkan pada perhitungan kelompok kedua yaitu memiliki nilai rata-rata penerimaan total sebesar Rp567,295,625,- biaya total dengan nilai rata-rata $R p 441,009,765$,sedangkan keuntungan rata-rata yang diperoleh yaitu sebesar Rp126,285,860,- R/C nilai rata-rata sebesar 12,734,- dan Payback Period sebesar 39,389 ,- 
Tabel 4. Perhitungan analisis usaha unit penangkapan Purse Seine di Ternate

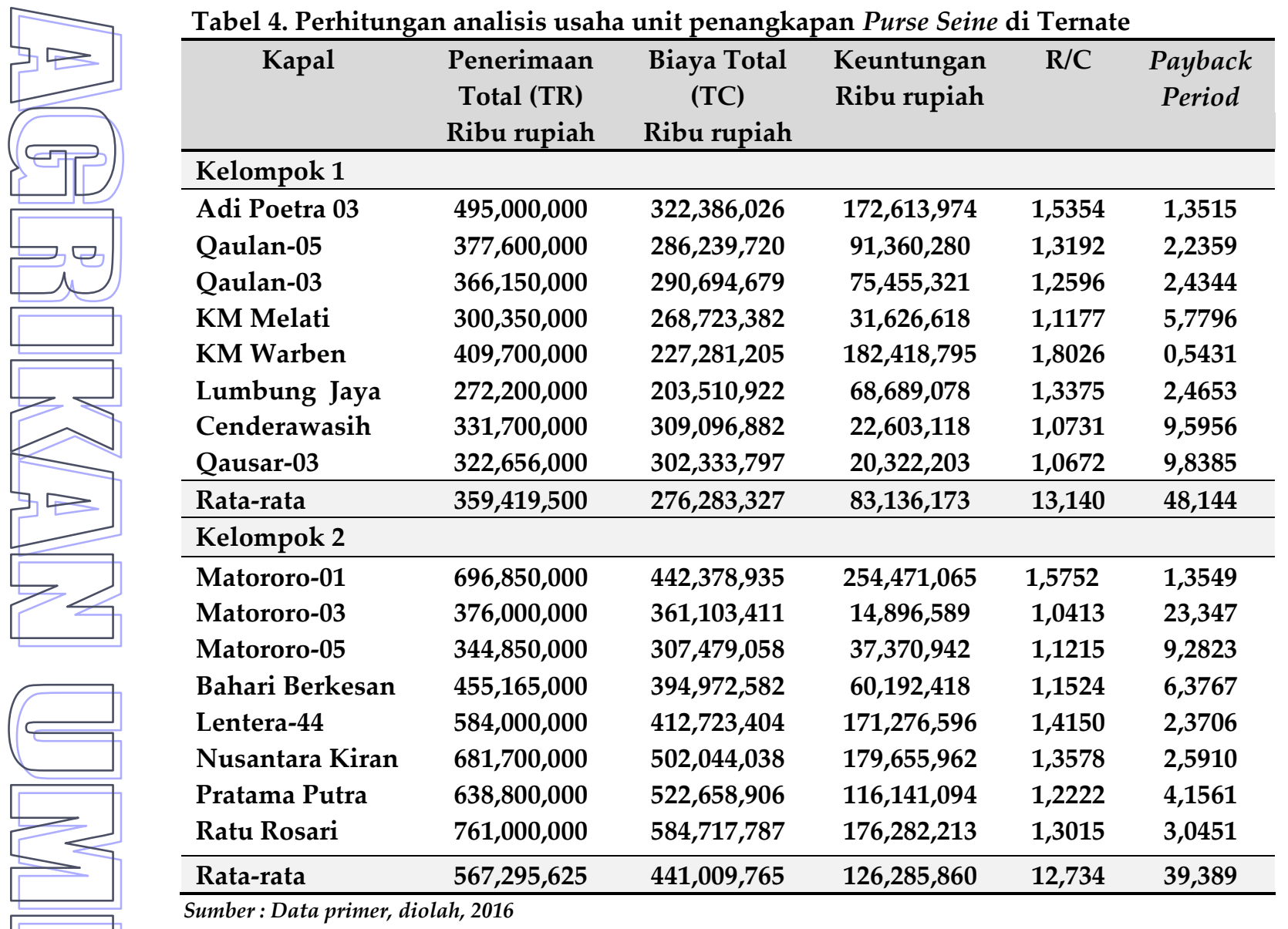

5.3. Analisis Efektifitas Unit Penangkapan Purse Seine di Ternate

Penilaian terhadap analisis efektifitas teknis dari unit penangkapan Purse Seine di PPN Ternate meliputi kriteria: produksi/Gross Tonage (GT) Kapal, produksi/kekuatan mesin (PK), produksi/bahan bakar, produksi/jumlah ABK. Dan produksi/luas jarring Purse Seine. Data mengenai produksi, ukuran kapal, kekuatan mesin, bahan bakar, jumlah ABK, dan luas jarring dari unit penangkapan Purse seine di Pelabuhan Perikanan Nusantara Ternate ditunjukan pada Tabel 5 .

Tabel 5 menunjukan jumlah produksi dari masing-masing unit penangkapan Purse Seine. Pada unit penangkapan Purse Seine kelompok satu jumlah produksi dalam satu tahun lebih rendah dibandingkan pada unit penangkapan Purse Seine kelompok dua. Jumlah produksi pada unit penangkapan Purse Seine kelompok dua lebih tinggi karena memiliki daerah penangkapan yang lebih jauh dimana persediaan ikan masih cukup besar. Frekuensi trip untuk unit penangkapan Purse Seine memiliki frekuensi yang sama yaitu selama 4 trip. Perbedaaan luas jangkauan daerah penangkapan ikan menyebabkan unit penangkapan Purse Seine berukuran 14 - 28 GT membawa perbekalan bahan bakar yang lebih banyak dibandingkan dengan unit penangkapan Purse Seine berukuran 5 - 6 GT yang membawa perbekalan bahan bakar lebih sedikit.

Kapal-kapal Purse Seine kelompok satu memiliki ukuran GT, dan kekuatan mesin yang lebih kecil dibandingkan dengan kapal-kapal Purse Seine kelompok dua yang memiliki ukuran GT dan kekuatan mesin yang lebih besar. Jumlah ABK yang dibawa pada unit penangkapan Purse Seine kelompok pertama sebanyak 13 sampai 15 orang, sedangkan pada unit penangkapan Purse Seine kelompok dua jumlah ABK sebanyak 17 sampai 20 0rang, jumlah ABK yang dibawah tergantung pada ukuran GT kapal. Luas jaring pada unit penangkapan Purse Seine kelompok dua lebih besar karena daerah penangkapan ikan pada unit penangkapan tersebut terletak didaerah gane barat dan Obi. Daerah tersebut memiliki daerah penangkapan ikan yang banyak, 
sedangkan pada Purse Seine kelompok pertama

memiliki luas jaring yang lebih kecil karena

beroperasi di Daerah Bacan dan Kayoa.

Tabel 5. Data Produksi, Ukuran Kapal, Kekuatan Mesin, Bahan Bakar, Jumlah ABK, dan Luas Jaring dari Unit Penangkapan Purse Seine di Pelabuhan Perikanan Nusantara Ternate

\begin{tabular}{lcccccc}
\hline \multicolumn{1}{c}{ Kapal } & $\begin{array}{c}\text { Produksi } \\
\text { (kg/tahu } \\
\text { n) }\end{array}$ & $\begin{array}{c}\text { Ukuran } \\
\text { Kapal } \\
(\mathrm{GT})\end{array}$ & $\begin{array}{c}\text { Kekuatan } \\
\text { Mesin (PK) }\end{array}$ & $\begin{array}{c}\text { Bahan } \\
\text { Bakar } \\
(\text { Liter) }\end{array}$ & $\begin{array}{c}\text { Jumlah } \\
\text { ABK } \\
\text { (orang) }\end{array}$ & $\begin{array}{c}\text { Luas } \\
\text { Jaring } \\
(\mathbf{m})\end{array}$ \\
\hline Kelompok 1 & & & & & & \\
\hline Adi Poetra -03 & 40,500 & 6 & 80 & 1,250 & 15 & 60 \\
Qaulan-05 & 31,810 & 6 & 80 & 1,250 & 15 & 60 \\
Qaulan-03 & 25,300 & 6 & 80 & 1,250 & 15 & 60 \\
KM Melati & 24,300 & 5 & 80 & 1,250 & 13 & 60 \\
KM Warben & 35,300 & 5 & 80 & 660 & 13 & 60 \\
Lumbung Jaya & 28,800 & 5 & 30 & 850 & 13 & 50 \\
Cenderawasih & 28,470 & 6 & 80 & 1,250 & 15 & 50 \\
Qausar-03 & 23,456 & 6 & 80 & 1,250 & 15 & 50 \\
\hline Rata-rata & 29,742 & 5,625 & 73,75 & 1,126 & 14,25 & 56,25 \\
\hline Kelompok 2 & & & & & & \\
\hline Matororo-01 & 56,700 & 14 & 94 & 1,650 & 17 & 60 \\
Matororo-03 & 39,600 & 14 & 94 & 1,650 & 17 & 70 \\
Matororo-05 & 29,100 & 14 & 94 & 1,650 & 17 & 70 \\
Bahari Berkesan & 36,590 & 16 & 80 & 1,650 & 18 & 70 \\
Lentera-44 & 50,000 & 18 & 95 & 1,650 & 18 & 75 \\
Nusantara Kira & 59,100 & 23 & 100 & 1,750 & 20 & 70 \\
Pratama Putra & 50,230 & 26 & 105 & 1,850 & 20 & 60 \\
Ratu Rosari & 66,000 & 28 & 120 & 1,850 & 20 & 80 \\
\hline Rata-rata & 48,415 & 19,125 & 97,75 & 1,713 & 18,375 & 63,975 \\
\hline Sumber: Data primer, diolah, 2016 & & & & &
\end{tabular}

Hasil perhitungan diatas dapat diketahui bahwa pada pada kapal kelompok pertama memiliki nilai produksi rata-rata sebesar 29,742,- ukuran kapal (GT) dengan nilai ratarata sebesar 5,625,- kekuatan mesin (PK) nilai rata-rata sebesar 73,75 ,- bahan bakar dengan nilai rata-rata 1,126,- dan jumlah ABK dengan nilai rata-rata 14,25 sedangkan luas jaring dengan nilai rata-rata sebesar 56,25 ,-

Sedangkan perhitungan pada kelompok kedua memiliki nilai produksi rata-rata sebesar 48,415 ,- ukuran kapal (GT) dengan nilai ratarata 19,125 ,- kekuatan mesin dengan nilai ratarata 97,75 ,- bahan bakar dengan nilai rata-rata sebesar 1,713,- dan jumlah ABK dengan nilai rata-rata 18,375 ,- sedangkan luas jaring dengan nilai rata-rata sebesar 63,975 ,-

Tabel 6 menunjukan tingkat efektivitas dari masing-masing kapal terhadap salah satu faktor teknis yang digunakan yaitu Gross Toneage (GT) kapal, kekuatan mesin (PK), bahan bakar, jumlah ABK, dan luas jaring Purse Seine. Hasil analisis menunjukan bahwa unit penangkapan Purse Seine kelompok pertama memiliki efektivitas yang lebih tinggi dibandingkan dengan kelompok kedua. Karena pada kelompok pertama produksi ikan dibagi dengan Gross Toneage (GT) kapal, kekuatan mesin (PK), bahan bakar (Liter) yang lebih rendah dibandingkan dengan kelompok kedua, sedangkan untuk $X 4$ dan $X 5$ kelompok pertama mimiliki nilai efektivitas lebih rendah karena produksi yang diperoleh dibagi dengan jumlah yang hampir sama dengan kelompok kedua, yaitu jumlah ABK dan luas jaring Purse Seine.

Perhitungan Efektivitas rata-rata pada kelompok pertama yaitu $X 1$ sebesar $5,325,-X 2$ nilai rata-rata sebesar $446,75,-$ dan pada $X 3$ nilai rata-rata sebesar $28,125,-X 4$ nilai rata-rata sebesar 2,096,- dan $X 5$ nilai rata-rata sebesar $529,25,-$, Sedangkan efektivitas rata-rata pada kelompok kedua yaitu $X 1$ memiliki nilai ratarata sebesar 2,610,- $X 2$ nilai rata-rata 492,- dan $X 3$ memiliki nilai rata-rata $28,125,-X 4$ nilai ratarata sebesar 2,619,- dan $X 5$ memiliki nilai ratarata sebesar 702,875 ,- 


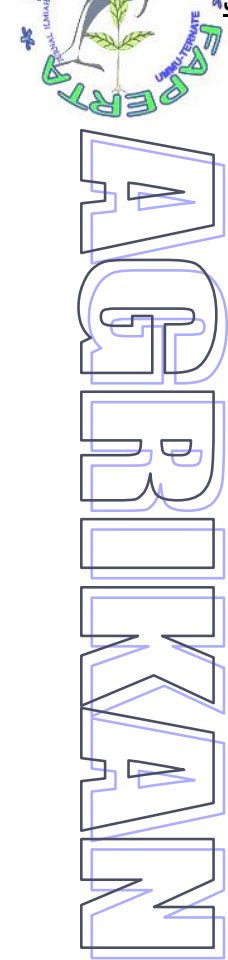

Tabel 6. Efektivitas Unit Penangkapan Purse Seine di Pelabuhan Perikanan Nusantara Ternate Tahun 2015

\begin{tabular}{|c|c|c|c|c|c|}
\hline Kapal & $X I$ & $X 2$ & X3 & $X 4$ & $X 5$ \\
\hline \multicolumn{6}{|l|}{ Kelompok 1} \\
\hline Adi Poetra -03 & 6,750 & 506 & 32 & 2,700 & 675 \\
\hline Qaulan-05 & 5,302 & 398 & 25 & 2,121 & 530 \\
\hline Qaulan-03 & 4,217 & 316 & 20 & 1,687 & 422 \\
\hline KM Melati & 4,860 & 304 & 19 & 1,869 & 405 \\
\hline KM Warben & 7,060 & 441 & 53 & 2,715 & 588 \\
\hline Lumbung Jaya & 5,760 & 960 & 34 & 2,215 & 576 \\
\hline Cenderawasih & 4,745 & 356 & 23 & 1,898 & 569 \\
\hline Qausar-03 & 3,909 & 293 & 19 & 1,564 & 469 \\
\hline Rata-rata & 5,325 & 446,75 & 28,125 & 2.096 & 529,25 \\
\hline \multicolumn{6}{|l|}{ Kelompok 2} \\
\hline Matororo-01 & 4,050 & 603 & 34 & 3,335 & 945 \\
\hline Matororo-03 & 2,829 & 421 & 24 & 2,329 & 566 \\
\hline Matororo-05 & 2,079 & 310 & 18 & 1,712 & 416 \\
\hline Bahari Berkesan & 2,287 & 457 & 22 & 2,033 & 523 \\
\hline Lentera-44 & 2,778 & 526 & 30 & 2,778 & 667 \\
\hline Nusantara Kirana & 2,570 & 591 & 34 & 2,955 & 844 \\
\hline Pratama Putra & 1,932 & 478 & 27 & 2,512 & 837 \\
\hline Ratu Rosari & 2,357 & 550 & 36 & 3,300 & 825 \\
\hline Rata-rata & 2,610 & 492 & 28,125 & 2,619 & 702,875 \\
\hline
\end{tabular}

Sumber : Data primer, diolah, 2016

Keterangan: $\quad X 1=$ Produksi $:$ Gross Toneage (GT) Kapal

$X 2=$ Produksi : Kekuatan mesin (PK)

X3 = Produksi : Bahan Bakar (Liter)

$X 4=$ Produksi $:$ Jumlah ABK (orang)

X5 = Produksi : Luas Jaring Purse Seine

Tabel 7. Penghitungan Fungsi Nilai Efektifitas Unit Penangkapan Purse Seine di Pelabuhan Perikanan Nusantara Ternate Tahun 2015

\begin{tabular}{lccccccc}
\hline \multicolumn{1}{c}{ Kapal } & $\mathrm{V}(\mathrm{XI})$ & $\mathrm{V}(\mathrm{X} 2)$ & $\mathrm{V}(\mathrm{X} 3)$ & $\mathrm{V}(\mathrm{X} 4)$ & $\mathrm{V}(\mathrm{X} 5)$ & $\mathrm{V}(\mathrm{X})$ & $\mathrm{UP}$ \\
\hline Adi Poetra -03 & 0.94 & 0.32 & 0.41 & 0.64 & 0.50 & 2.81 & 4 \\
Qaulan-05 & 0.66 & 0.16 & 0.22 & 0.31 & 0.23 & 1.36 & 9 \\
Qaulan-03 & 0.45 & 0.03 & 0.07 & 0.07 & 0.03 & 0.65 & 14 \\
KM Melati & 0.57 & 0.02 & 0.02 & 0.17 & 0.00 & 0.78 & 13 \\
KM Warben & 1.00 & 0.22 & 1.00 & 1.00 & 0.34 & 3.56 & 1 \\
Lumbung Jaya & 0.75 & 1.00 & 0.45 & 0.37 & 0.32 & 2.89 & 3 \\
Cenderawasih & 0.55 & 0.09 & 0.14 & 0.19 & 0.30 & 1.27 & 11 \\
Qausar-03 & 0.39 & 0.00 & 0.03 & 0.00 & 0.12 & 0.54 & 15 \\
Matororo-01 & 0.41 & 0.46 & 0.47 & 1.00 & 1.00 & 3.34 & 2 \\
Matororo-03 & 0.17 & 0.19 & 0.18 & 0.43 & 0.30 & 1.27 & 10 \\
Matororo-05 & 0.03 & 0.02 & 0.00 & 0.08 & 0.02 & 0.15 & 16 \\
Bahari Berkesan & 0.07 & 0.25 & 0.13 & 0.26 & 0.22 & 0.93 & 12 \\
Lentera-44 & 0.16 & 0.35 & 0.35 & 0.69 & 0.48 & 2.03 & 7 \\
Nusantara Kirana & 0.12 & 0.45 & 0.45 & 0.79 & 0.81 & 2.62 & 6 \\
Pratama Putra & 0.00 & 0.28 & 0.27 & 0.53 & 0.80 & 1.88 & 8 \\
Ratu Rosari & 0.08 & 0.39 & 0.50 & 0.98 & 0.78 & 2.73 & 5 \\
\hline
\end{tabular}

Sumber : Data primer, diolah, 2016

Selanjutnya dilakukan penghitungan fungsi nilai dari masing-masing kriteria teknis untuk mempermudah pengambilan keputusan mengenai analisis efektivitas secara keseluruhan. Hasil dari analisis efektivitas dengan fungsi nilai dari unit penangkapan Purse Seine di Pelabuhan Perikanan Nusantara 
Ternate dapat dilihat pada Tabel 14 (Lihat lampiran 2).

Dari Tabel diatas dapat dilihat bahwa pada kelompok pertama kapal KM-Warben memiliki nilai efektivitas tertinggi pada $\mathrm{V}(\mathrm{X} 1)$, produksi bagi dengan GT kapal, V(X3), produksi bagi bahan bakar, dan V(X4), produksi dibagi dengan jumlah ABK. Sehingga kapal KM-Warben memiliki V(X) 3.56 tertinggi dan menduduki prioritas pertama.

5.4. Analisis Efisiensi Unit Penangkapan Purse Seine di Ternate

Efisiensi merupakan suatu ukuran dalam membandingkan rencana penggunaan masukan dengan penggunaan yang direalisasikan atau perkataan lain penggunaan yang sebenarnya (Mulyamah, 1987). Nilai produksi kotor masing-masing pada unit kapal Purse Seine di dapat dari produksi ikan selama satu tahun di Pelabuhan Perikanan Nusantara Ternate, bisa dilihat pada Tabel 8. Tabel 8, dapat dilihat bahwa nilai produksi pada unit kapal Purse Seine kelompok dua lebih besar dibandingkan dengan kelompok pertama, dengan nilai produksi rata-rata sebesar Rp567,295,625,- dan untuk nilai produksi ratarata pada kelompok pertama sebesar Rp359,419,500,- Tabel efisiensi ekonomis dari unit penangkapan Purse Seine dapat dilihat pada Tabel 9.

Tabel 8. Data Nilai Produksi, Ukuran Kapal, Kekuatan Mesin, Bahan Bakar, Jumlah ABK, dan Luas Jaring dari Unit Penangkapan Purse Seine di Pelabuhan Perikanan Nusantara Ternate

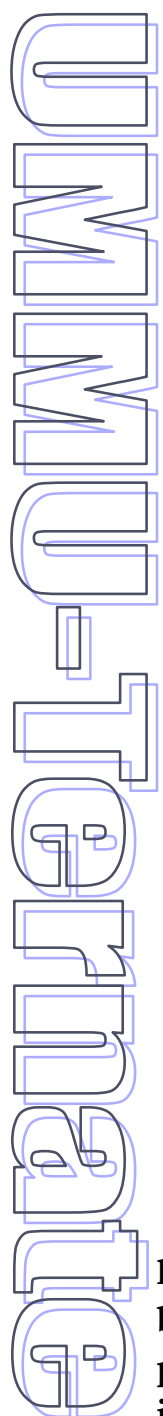

\begin{tabular}{lcccccc}
\hline \multicolumn{1}{c}{ Kapal } & $\begin{array}{c}\text { Nilai Produksi } \\
\text { Kotor (RP) }\end{array}$ & $\begin{array}{c}\text { Ukuran } \\
\text { Kapal } \\
\text { (GT) }\end{array}$ & $\begin{array}{c}\text { Kekuatan } \\
\text { Mesin } \\
\text { (PK) }\end{array}$ & $\begin{array}{c}\text { Bahan } \\
\text { Bakar } \\
\text { (Liter) }\end{array}$ & $\begin{array}{c}\text { Jumlah } \\
\text { ABK } \\
\text { (Orang) }\end{array}$ & $\begin{array}{c}\text { Luas } \\
\text { Jaring } \\
(\mathrm{m})\end{array}$ \\
\hline Kelompok 1 & & & & & & \\
\hline AdiPoetra-03 & $495,000,000$ & 6 & 80 & 1,250 & 15 & 60 \\
Qaulan-05 & $377,600,000$ & 6 & 80 & 1,250 & 15 & 60 \\
Qaulan-03 & $366,150,000$ & 6 & 80 & 1,250 & 15 & 60 \\
KM Melati & $300,350,000$ & 5 & 80 & 1,250 & 13 & 60 \\
KM Warben & $409,700,000$ & 5 & 80 & 660 & 13 & 60 \\
Lumbung Jaya & $272,200,000$ & 5 & 30 & 850 & 13 & 50 \\
Cenderawasih & $331,700,000$ & 6 & 80 & 1,250 & 15 & 50 \\
Qausar-03 & $322,656,000$ & 6 & 80 & 1,250 & 15 & 50 \\
\hline Rata-rata & $359,419,500$ & 5,625 & 73,75 & 1,126 & 14,25 & 56,25 \\
\hline Kelompok 2 & & & & & & 17 \\
\hline Matororo-01 & $696,850,000$ & 14 & 94 & 1,650 & 17 & 60 \\
Matororo-03 & $376,000,000$ & 14 & 94 & 1,650 & 17 & 70 \\
Matororo-05 & $344,850,000$ & 14 & 94 & 1,650 & 17 & 70 \\
Bahari Berkesan & $455,165,000$ & 16 & 80 & 1,650 & 18 & 70 \\
Lentera-44 & $584,000,000$ & 18 & 95 & 1,650 & 18 & 75 \\
Nusantara Kiran & $681,700,000$ & 23 & 100 & 1,750 & 20 & 70 \\
Pratama Putra & $638,800,000$ & 26 & 105 & 1,850 & 20 & 60 \\
Ratu Rosari & $761,000,000$ & 28 & 120 & 1,850 & 20 & 80 \\
\hline Rata-rata & $567,295,625$ & 19,125 & 97,75 & 1,713 & 18,375 & 69,375 \\
\hline Sumber: Data primer, diolah, 2016 & & & & &
\end{tabular}

Tabel 9, menunjukan bahwa kapal pada kelompok kedua memiliki nilai efisiensi lebih besar pada $X 2, X 4$ dan $X 5$. Karena nilai produksi dibagi dengan kekuatan mesin (PK), jumlah ABK, dan luas jaring Purse Seine yang kekuatan, jumlah dan luas jaring nya hampir sama dengan kelompok pertama. Sedangkan unit kapal kelompok pertama memiliki nilai efisiensi lebih besar pada $X 1$, dan $X 3$, karna nilai produksi yang dibagi dengan Gross Toneage (GT) kapal, dan bahan bakar lebih sedikit dari kelompok kedua. Penghitungan fungsi nilai efisiensi seperti yang terlihat pada Tabel 10. 
Tabel 9. Efisiensi Ekonomis Unit Penangkapan Purse Seine di Pelabuhan Perikanan Nusantara Ternate

\begin{tabular}{|c|c|c|c|c|c|}
\hline Kapal & $X 1$ & $X 2$ & $X 3$ & $X 4$ & $X 5$ \\
\hline \multicolumn{6}{|l|}{ Kelompok 1} \\
\hline AdiPoetra-03 & $82,500,000$ & $6,187,500$ & 396,000 & $33,000,000$ & $8,250,000$ \\
\hline Qaulan-05 & $62,933,333$ & $4,720,000$ & 302,080 & $25,173,333$ & $6,293,333$ \\
\hline Qaulan-03 & $61,025,000$ & $4,576,875$ & 292,920 & $24,410,000$ & $6,102,500$ \\
\hline KM Melati & $60,070,000$ & $3,754,375$ & 240,280 & $23,103,846$ & $5,005,833$ \\
\hline KM Warben & $81,940,000$ & $5,121,250$ & 620,758 & $31,515,385$ & $6,828,333$ \\
\hline Lumbung Jaya & $54,440,000$ & $9,073,333$ & 320,235 & $20,938,462$ & $5,444,000$ \\
\hline Cenderawasih & $55,283,333$ & $4,146,250$ & 265,360 & $22,113,333$ & $6,634,000$ \\
\hline Qausar-03 & $53,776,000$ & $4,033,200$ & 258,125 & $21,510,400$ & $6,453,120$ \\
\hline Rata-rata & $63,995,958$ & $5,201,598$ & 336,970 & $25,220,595$ & $6,373,390$ \\
\hline \multicolumn{6}{|l|}{ Kelompok 2} \\
\hline Matororo-01 & $49,775,000$ & $7,413,298$ & 422,333 & $40,991,176$ & $11,614,167$ \\
\hline Matororo-03 & $26,857,143$ & $4,000,000$ & 227,879 & $22,117,647$ & $5,371,429$ \\
\hline Matororo-05 & $24,632,143$ & $3,668,617$ & 209,000 & $20,285,294$ & $4,926,429$ \\
\hline Bahari Berkesan & $28,447,813$ & $5,689,563$ & 275,858 & $25,286,944$ & $6,502,357$ \\
\hline Lentera-44 & $32,444,444$ & $6,147,368$ & 353,939 & $32,444,444$ & $7,786,667$ \\
\hline Nusantara Kirana & $29,639,130$ & $6,817,000$ & 389,543 & $34,085,000$ & $9,738,571$ \\
\hline Pratama Putra & $24,569,231$ & $6,083,810$ & 345,297 & $31,940,000$ & $10,646,667$ \\
\hline Ratu Rosari & $27,178,571$ & $6,341,667$ & 411,351 & $38,050,000$ & $9,512,500$ \\
\hline Rata-rata & $30,442,934$ & $5,770,165$ & 329,400 & $30,650,063$ & $8,262,348$ \\
\hline \multicolumn{6}{|c|}{ Sumber : Data primer, diolah, 2016} \\
\hline \multicolumn{6}{|c|}{ Keterangan: $\begin{aligned} X 1 & =\text { Nilai Produksi }: \text { Gross Toneage }(\text { GT) Kapal } \\
X 2 & =\text { Nilai Produksi }: \text { Kekuatan mesin }(\text { PK) } \\
X 3 & =\text { Nilai Produksi }: \text { Bahan Bakar }(\text { Liter }) \\
X 4 & =\text { Nilai Produksi }: \text { Jumlah ABK (orang) } \\
X 5 & =\text { Nilai Produksi }: \text { Luas Jaring Purse Seine }\end{aligned}$} \\
\hline
\end{tabular}

Tabel 10. Penghitungan fungsi nilai efisiensi ekonomis unit penangkapan Purse Seine di Pelabuhan Perikanan Nusantara Ternate

\begin{tabular}{lccccccc}
\hline \multicolumn{1}{c}{ Kapal } & $\mathrm{V}(\mathrm{XI})$ & $\mathrm{V}(\mathrm{X} 2)$ & $\mathrm{V}(\mathrm{X} 3)$ & $\mathrm{V}(\mathrm{X} 4)$ & $\mathrm{V}(\mathrm{X} 5)$ & $\mathrm{V}(\mathrm{X})$ & $\mathrm{UP}$ \\
\hline Adi Poetra -03 & 1.00 & 0.47 & 0.45 & 0.61 & 0.50 & 3.03 & 3 \\
Qaulan-05 & 0.66 & 0.19 & 0.23 & 0.24 & 0.20 & 1.52 & 9 \\
Qaulan-03 & 0.63 & 0.17 & 0.20 & 0.20 & 0.18 & 1.38 & 10 \\
KM Melati & 0.61 & 0.02 & 0.08 & 0.14 & 0.01 & 0.86 & 14 \\
KM Warben & 1 & 0.27 & 1.00 & 0.54 & 0.28 & 3.09 & 2 \\
Lumbung Jaya & 0.52 & 1.00 & 0.27 & 0.03 & 0.08 & 1.90 & 8 \\
Cenderawasih & 0.53 & 0.09 & 0.14 & 0.09 & 0.26 & 1.11 & 11 \\
Qausar-03 & 0.50 & 0.07 & 0.12 & 0.06 & 0.23 & 0.98 & 13 \\
Matororo-01 & 0.44 & 0.69 & 0.52 & 1.00 & 1.00 & 3.65 & 1 \\
Matororo-03 & 0.04 & 0.06 & 0.05 & 0.09 & 0.07 & 0.31 & 15 \\
Matororo-05 & 0.00 & 0.00 & 0.00 & 0.00 & 0.00 & 0.00 & 16 \\
Bahari Berkesan & 0.07 & 0.37 & 0.16 & 0.24 & 0.24 & 1.08 & 12 \\
Lentera-44 & 0.14 & 0.46 & 0.35 & 0.59 & 0.43 & 1.97 & 7 \\
Nusantara Kirana & 0.09 & 0.58 & 0.44 & 0.67 & 0.72 & 2.50 & 5 \\
Pratama Putra & 0 & 0.45 & 0.33 & 0.56 & 0.86 & 2.20 & 6 \\
Ratu Rosari & 0.05 & 0.49 & 0.49 & 0.86 & 0.69 & 2.58 & 4 \\
\hline
\end{tabular}

Sumber: Data primer, diolah, 2016 
Pada Tabel 10 dapat dilihat bahwa kapal Matororo-01 memiliki nilai efisiensi tertinggi pada $V(X 4)$ nilai produksi bagi dengan jumlah $A B K$, dan $V(X 5)$ nilai produksi bagi luas jaring Purse Seine. Dengan $\mathrm{V}(\mathrm{X}) 3.65$,- tertinggi dan menduduki prioritas pertama.

\section{KESIMPULAN DAN SARAN}

4.1. Kesimpulan

Berdasarkan hasil analisis yang telah diuraikan sebelumnya maka penelitian tentang analisis tingkat efisiensi dan efektifitas operasi kapal purse seine di pelabuhan perikanan nusantara ternate Provinsi maluku utara. Dapat disimpulkan sebagai berikut.

1. Hasil dari Analisis efisiensi dan efektifitas terhadap kegiatan operasi dan pengembangan pada kapal Purse Seine kelompok pertama dengan ukuran GT kecil memperoleh nilai rata-rata 29,742,- dan kelompok kedua dengan GT besar memiliki rata-rata sebanyak 48,415 ,-

\subsection{Saran}

Saran yang perlu dipertimbangkan dari penelitian ini adalah sebagai berikut :

1. Perlu disediakan data yang lebih lengkap lagi di Pelabuhan Perikanan Nusantara Ternate

2. Kapal dengan ukuran GT lebih kecil juga mampu bersaing dengan kapal yang berukuran GT lebih besar.

3. Diharapkan Pemerintah harus lebih teliti dalam memperhatikan proses penangkapan ikan menggunkan alat tangkap Purse Seine agar tidak terjadi kesalahan yang dapat dilakukan oleh para ABK/Nelayan.

\section{DAFTAR PUSTAKA}

Ayodhyoa 1981. Metode penangkapan ikan, Bogor : program studi pemanfaatan sumber daya perikanan, fakultas perikanan, dan ilmu kelautan, institute pertanian Bogor.

Christanti, N. 2005. Tingkat Penyediaan dan Kebutuhan Es untuk Kapal Ikan di Pelabuhan Perikanan Nusantara Pekalongan [Skripsi]. Bogor: Departemen Pemanfaatan Sumberdaya Perikanan, Fakultas Perikanan dan Ilmu Kelautan, Institut Pertanian Bogor.

[DKP] Departemen Kelautan dan Perikanan. 2004. Surat Keputusan MenteriKelautan dan Perikanan Nomor 10 Tahun 2004 tentang klasifikasi pelabuhan perikanan di Indonesia. Jakarta: DKP. Departemen Kelautan dan Perikanan. 2005. Statistik Pelabuhan PerikananNusantara Pekalongan 2004. Direktorat Jenderal Perikanan Tangkap. Jakarta:DKP.

Departemen Kelautan dan Perikanan. 2009. Peraturan Menteri Kelautan dan Perikanan Nomor 2 Tahun 2006 tentang organisasi dan tata kerja pelabuhan perikanan. Jakarta: DKP.

Fiqrin 2010, Tentang ikan / purse seine / diakses pada hari rabu tanggal 11 januari 2012 pukul 14: 39

Haluan, J. dan Nurani, TW. 1988. Penerapan Metode Scoring dalam PenelitianTeknologi Penangkapan Ikan yang Sesuai Untuk Dikembangkan di SuatuWilayah Perairan. Buletin PSP Vol II, No.1 Juni 1988. Bogor: FakultasPerikanan dan Ilmu Kelautan.

Mulyadi, M. D. 2007. Analisis Pendaratan dan Penanganan Hasil Tangkapan danFasilitas Terkait di Pelabuhan Perikanan Nusantara (PPN) Pekalongan[Skripsi]. Bogor: Departemen Pemanfaatan Sumberdaya Perikanan, Fakultas Perikanan dan Ilmu Kelautan, Institut Pertanian Bogor.

[PPN Ternate] Pelabuhan Perikanan Nusantara Ternate. 2000. Master Plan

Pelabuhan Perikanan Nusantara Ternate. Ternate: PPNP. Ternate] Pelabuhan Perikanan Nusantara Ternate. 2003. Laporan Tahunan Pelabuhan Perikanan Nusantara Pekalongan Tahun 2002. Ternate: PPNP.

Ternate] Pelabuhan Perikanan Nusantara Ternate. 2007. Laporan Tahunan 2006. Ternate: PPNP.

Suharto, R. T. 2003. Efisiensi Teknis-Ekonomis Usaha Penangkapan Ikan Pelagis Besar dengan Alat Tangkap Gillnet dan Rawai Tuna (Longline) di Cilacap. [Skripsi] Bogor: Departemen Pemanfaatan Sumberdaya Perikanan, Fakultas Perikanan dan Ilmu Kelautan, Institut Pertanian Bogor. 
Sutopo 2003, Teknologi Benih. PT. Raja Grafindo Persada Jakarta.

Hasibuan, 1984. Efisiensi Biaya Produksi, Edisi ketiga jilid 2.

Von Brandt, A. 1984. Fish Catching Methods of the World. London: Fishing News Books Ltd.

Purbayanto et al. 2004. Kajian teknis kemungkinan pengalihan pengaturan pengijinan dari GT menjadi volume palka pada kapal ikan.
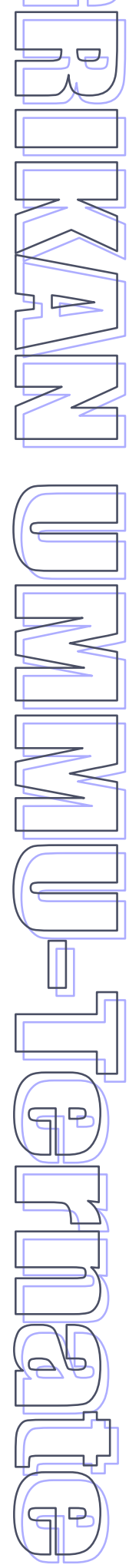